\title{
The Polymerization of Methyl Methacrylate Using Cu(II) Benzamidinate Complexes
}

\author{
Koichi SHIBAYAMA \\ Minase Research Laboratories, R\&D Institute, High Performance Plastics Company, Sekisui Chemical Co., Ltd., \\ Shimamoto, Osaka 618-8589, Japan \\ Graduate School of Science and Technology, Kumamoto University, Kurokami, Kumamoto 860-8555, Japan
}

(Received May 7, 2003; Accepted July 1, 2003)

\begin{abstract}
The polymerization of methyl methacrylate (MMA) by $\mathrm{Cu}$ (II) amidinate complexes in combination with alkyl aluminum complexes is reported. The preferred alkylating agent is methylaluminoxane (MAO) in terms of improved yield and catalyst activity. Mechanistic studies indicate that the active species is a copper(I) complex.

KEY WORDS Poly(methyl methacrylate) / Copper Complex / Alkyl Aluminum Complex / Lewis Acid / Controlled Polymerization /
\end{abstract}

A great challenge in the polymerization field has been the development of transition metal catalysts that are active toward the polymerization of polar and functional monomers. Themes have included ligands that are alternatives to the cyclopentadienyl ${ }^{1}$ ligand and the use of later (e.g., Group VIII) transition metals as the base metals of the catalyst. ${ }^{2}$

Of the various alternatives investigated, dinitrogenchelating ligands have been common. ${ }^{3}$ In this regard, I have been interested in using the benzamidinate (Bam) as a ligand for transition metal catalysts. Jordan has recently reported the use of amidinates as ligands for aluminum complexes that are active toward the polymerization of ethylene. ${ }^{4}$ Novak et al. have reported the use of Bam as ligands for both copper(I) and copper(II) complexes which catalyze the living polymerization of carbodiimides. ${ }^{5}$ In the later case, the amidinate moiety is actually the initiator and is delivered the end of the growing polymer chain (eq 1).

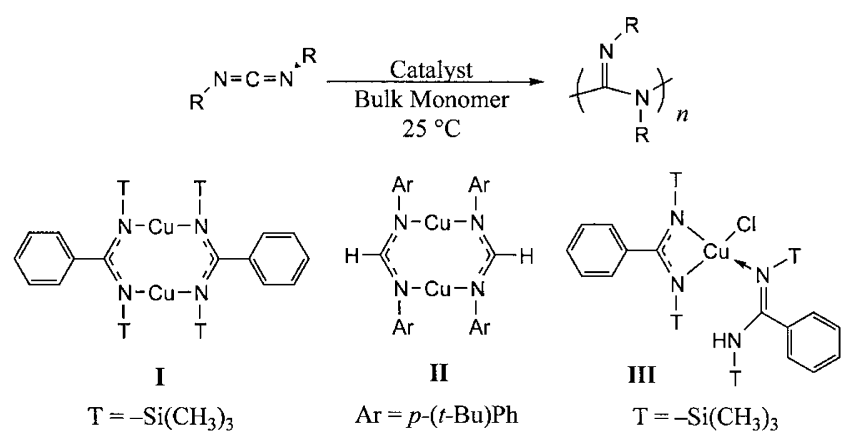

Polymerization of carbodiimides does demonstrate that copper displays a good level of tolerance for functional groups. For this reason, I have elected to investigate the use of $\mathrm{Cu}(\mathrm{Bam})$ complexes for the polymerization of methyl methacrylate (MMA). Specifically, I would like to report herein the use of $\mathrm{Cu}(\mathrm{Bam})$ com- plexes combination with alkylaluminiums or methylaluminoxane (MAO) as catalysts for the polymerization of MMA.

\section{RESULTS AND DISCUSSION}

\section{Synthesis of Copper(II) Bam complexes}

The copper(II) Bam complex, III was synthesized using modified literature procedures (eq 2). Complex III is isolated as a monomeric compound containing a hydrolyzed amidine coordinated to the copper center. The synthesis utilizes wet acetonitrile solvent that provides the necessary source of water. No conditions were ever identified that allowed for the isolation of the $\mathrm{Cu}(\mathrm{II})(\mathrm{Bam})$ complex free of bound amidine.

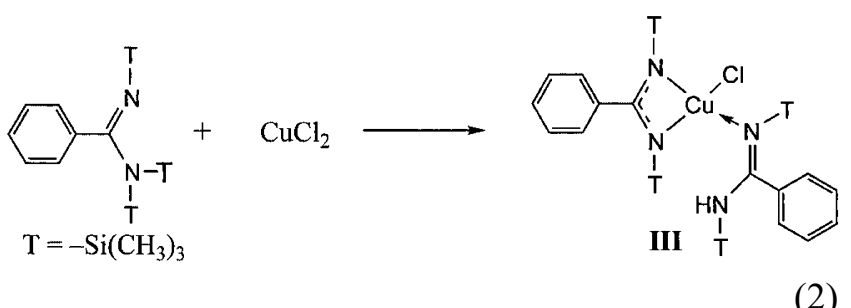

\section{Polymerization Behavior}

In order to provide a frame of reference for this work, the catalytic activity of simple $\mathrm{Cu}$ salts in combination with methylaluminoxane (MAO) was investigated. Not surprisingly, not many $\mathrm{Cu}$ complexes showed no activity to polymerization of a wide range of monomers, but some combinations are mildly active. For example, $\mathrm{Cu}(\mathrm{acac})_{2}$ in combination with $\mathrm{MAO}(\mathrm{Al} / \mathrm{Cu}=100$ or 1000) gave a catalyst that yielded only $16-18 \%$ of oligomeric poly(methyl methacrylate) (PMMA) $\left(M_{\mathrm{n}} \approx\right.$ 2000) after $24 \mathrm{~h}$. Switching to complex III possessing the Bam ligand gave much better results. Although no polymer was obtained with vinyl acetate and only 
trace activity was observed with styrene, it was discovered that III was highly active for the polymerization of MMA (e.g., quantitative yields of PMMA) at room temperature (eq 3 ).

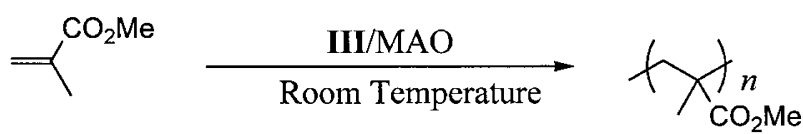

(Syndiotactic rich)

Without alkylaluminum cocatalysts, no polymer was obtained. However, III in the presence of aluminum alkyls (MAO or tri(isobutyl) aluminum (TIBA)) led to active catalysts. The rate of polymerization was over an order of magnitude faster using MAO than TIBA as a cocatalyst $\left(1.07 \times 10^{-2} \mathrm{~mol}^{-1} \mathrm{~s}^{-1} v \mathrm{~s}\right.$. $3.44 \times 10^{-3} \mathrm{~mol}^{-1} \mathrm{~s}^{-1}$ ). In the case of TIBA as the cocatalyst, a black precipitate was noted, which is indicative of reduction of the catalyst to copper metal. Furthermore, the molecular weight $\left(M_{\mathrm{n}}\right)$ of the polymer increased from approximately 7000 to greater than 68000 in going from TIBA to MAO.

By inference, the role of the alkyl aluminum cocatalyst appears to be as an alkylating agent rather than an activating Lewis acid. Control experiments using the triisopropoxy aluminum, $\mathrm{Al}(\mathrm{O}-i \mathrm{Pr})_{3}$, in combination with the Bam complex III gave no polymer.

The previously reported carbodiimide polymerizations demonstrated that both copper(I) and copper(II) complexes were active catalysts. In order to address the question of the oxidation state of the active catalyst in this system, ESR studies were conducted. The initial strong ESR signal associated with the copper(II) complex, III, disappeared upon treatment with MAO indicating a reduction of the copper(II) to the EPR-silent, copper(I) oxidation state. The reduction in activity and the appearance of the black precipitate noted when using TIBA is indicative of an over-reduction to $\mathrm{Cu}(0)$.

Nuclear magnetic resonance (NMR) studies indicates that the tacticity is different for III with MAO and TIBA, and both are different from the materials obtained using either anionic ${ }^{6}$ or radical ${ }^{7}$ initiators (Table I).

The change in tacticity lends evidence to the fact that these polymerizations propagate through a copper mediated process. Further mechanistic studies are currently underway.

\section{CONCLUSIONS}

We have demonstrated that unlike other copper complexes, $\mathrm{Cu}(\mathrm{II})$ Bam complexes in combination with alkyl aluminum compounds will effect the polymeriza-
Table I. Diad tacticities for PMMA obtained using III and alkyl aluminum cocatalysts

\begin{tabular}{lrrrc}
\hline Catalyst/Cocatalyst & \multicolumn{1}{c}{$m m$} & \multicolumn{1}{c}{$m r$} & \multicolumn{1}{c}{$r r$} & $(m)$ \\
\hline III/MAO & 26.4 & 29.9 & 43.6 & 41.4 \\
III/TIBA & 5.1 & 29.1 & 65.8 & 19.7 \\
Radical (AIBN) & 6.0 & 34.7 & 61.3 & 21.4 \\
Anionic $\left(t\right.$-BuMgBr) $^{7}$ & 96.5 & 3.2 & 0.3 & 98.1 \\
\hline
\end{tabular}

tion of MMA at room temperature. Of the two alkylating agents investigated, MAO was found to be superior to TIBA in terms of polymer yield, reaction rate, and purity of the product. Mechanistic studies indicate that the active species is in the copper(I) oxidation state. Finally, the tacticity of the polymer produced differs substantially from the materials obtained from either radical or anionic initiated processes lending evidence that the polymerization proceeds through a copper mediated mechanism.

\section{EXPERIMENTAL}

\section{General Procedures}

Unless otherwise noted, all synthetic operations were carried out under inert gas (nitrogen or argon) using Schlenk techniques or in a glove box. Toluene and methyl methacrylate were distilled from $\mathrm{CaH}_{2}$ under a argon atmosphere immediately prior to use. Acetonitrile was purchased from Aldrich as Acetonitrile anhydrous, $99.8 \%$, water $<0.005 \%$, and used without further purification. Triisobutylalumium/toluene solution and methylaluminoxane (MAO) were purchased from Tosoh-Akzo and used without further purification. $N, N^{\prime}, N^{\prime}$-Tris(trimethylsilyl)benzamidine was prepared according to literature methods. ${ }^{8}$ Anhydrous $\mathrm{CuCl}_{2}$ was prepared by drying under vacuum at $100^{\circ} \mathrm{C}$ of the $\mathrm{CuCl}_{2} \% n \mathrm{H}_{2} \mathrm{O}$ which was recrystallized from hot $\mathrm{HCl}$ aq. (ca. $2 \mathrm{~N})$. NMR spectra were recorded on a Bruker DRX-300 NMR spectrometer. ${ }^{1} \mathrm{H} N M R$ and ${ }^{13} \mathrm{C}$ NMR spectra were referenced to a residual resonance of the solvent employed. Infrared spectra were recorded on a PerkinElmer 2000 Series Fourier transform infrared spectrometer. ESR spectra were recorded on a JEOL JES-TE200 ESR spectrometer. Gel permeation chromatography (GPC) was performed on a JASCO 802$\mathrm{SC}$ with Shodex column KF-80 M and tetrahydrofuran (THF) as the eluant $\left(1.0 \mathrm{~mL} \mathrm{~min}^{-1}\right.$.).

\section{The Synthesis of Copper(BAM) Complex}

After the atmosphere of the $100 \mathrm{~mL}$ Schlenk flask was changed to argon, the flask was charged with $N, N^{\prime}, N^{\prime}$-tris(trimethylsilyl)benzamidine $(3.00 \mathrm{~g}$, $8.91 \mathrm{mmol})$, dehydrated $\mathrm{CuCl}_{2}(0.599 \mathrm{~g}, 4.45 \mathrm{mmol})$, a magnetic stir bar, and $28.6 \mathrm{~mL}$ of anhydrous ace- 
tonitrile. The resulting solution was stirred for $15 \mathrm{~h}$. The reaction mixture was filtered. The filtrate obtained was condensed by vacuum. The green precipitate was filtered and recrystallized from THF and n-hexane. Yield (2.15 g, 77.1\%). IR( $\left.\mathrm{CHCl}_{3}\right): 3495(\mathrm{~m}), 3358(\mathrm{w})$, 3312(w), 3247(w), 1646(s), 1605(m), 1596(m), 1571(m), 1559(w), 1501(w), 1456(w). Anal. Calcd for $\mathrm{C}_{26} \mathrm{H}_{47} \mathrm{~N}_{4} \mathrm{Si}_{4} \mathrm{CuCl}$ : C, 49.72; $\mathrm{H}, 7.54 ; \mathrm{N}, 8.92 ; \mathrm{Cl}$, 5.80. Found: C, 49.15; H, 7.41; N, 9.19; Cl, 5.59.

Acknowledgments. Fruitful discussions with Professor Bruce M. Novak, North Carolina State University, are gratefully acknowledged.

\section{REFERENCES}

1. a) D. W. Stephan, J. C. Stewart, F. Guerin, R. E. v. H. Spence, W. Xu, and D. G. Harrison, Organometallics, 18, 1116 (1999). b) D. W. Stephan, F. Guerin, R. E. v. H. Spence, L. Koch, X. Gao, S. J. Brown, J. W. Swabey, Q. Wang, W. Xu, P. Zoricak, and D. G. Harrison, Organometallics, 18, 2046 (1999).

2. a) L. K. Johnson, C. M. Killian, and M. S. Brookhart, J. Am. Chem. Soc., 117, 6414 (1995).

b) C. M. Killian, D. J. Tempel, L. K. Johnson, and M. S.
Brookhart, J. Am. Chem. Soc., 118, 11664 (1996).

c) S. Mecking, L. K. Johnson, L. Wang, and M. S. Brookhart, J. Am. Chem. Soc., 120, 888 (1998).

d) B. L. Small, M. Brookhart, and A. M. A. Bennett, J. Am. Chem. Soc., 120, 4049 (1998).

e) C. Wang, S. Friedrich, T. R. Younhkin, R. T. Li, R. H. Grubbs, D. A. Bansleben, and M. W. Day, Organometallics, 17, 3149 (1998).

3. a) J. D. Scollard and D. H. McConville, J. Am. Chem. Soc., 118, 10008 (1996).

b) T. H. Warren, R. R. Schrock, and W. M. Davis, Organometallics, 17, 308 (1998).

c) F. G. N. Cloke, T. J. Geldach, P. B. Hitchcock, and J. B. Love, J. Organomet. Chem., 506, 343 (1996).

4. a) M. P. Coles and R. F. Jordan, J. Am. Chem. Soc., 119, 8125 (1997).

b) M. P. Coles, D. C. Swenson, and R. F. Jordan, Organometallics, 16, 5183 (1997).

5. K. Shibayama, S. W. Seidel, and B. M. Novak, Macromolecules, 30, 3159 (1997).

6. R. Chujo, K. Hatada, R. Kitamaru, T. Kitayama, H. Sato, and Y. Tanaka, Polym. J., 19, 413 (1987).

7. K. Hatada, K. Ute, K. Tanaka, Y. Okamoto, and T. Kitayama, Polym. J., 18, 1037 (1986).

8. A. R. Sanger, Inorg. Nucl. Chem. Lett., 9, 351 (1973). 